\title{
"Madness and Despair are a Force": Global Mental Health, and How People and Cultures Challenge the Hegemony of Western Psychiatry
}

\author{
Roberto Beneduce $^{1}$ (D)
}

Published online: 15 November 2019

(C) Springer Science+Business Media, LLC, part of Springer Nature 2019

\begin{abstract}
The author suggests to consider some important hidden connections in Global Mental Health (GMH) discourse and interventions, above all the political meaning of suffering and symptoms, the power of psychiatric diagnostic categories (both Western and traditional) to name and to occult at once other conflicts, and the implicit criticism expressed by so-called local healing knowledge and its epistemologies. These issues, by emphasizing the importance to explore other ontologies, help to understand the perplexity and resistance that GMH and its agenda meet among many scholars and professionals, who denounce the risks of reproducing and globalizing Western hegemonic values concerning health, illness, and healing.
\end{abstract}

Keywords "Palimpsest nature" of psychiatric disorders ·

Hegemonic dimensions of psychiatric diagnostic apparatus · Crypto-racism · Indocile suffering . "Minor" and "subjugated" (healing) knowledge

\section{Introduction}

The vast number of questions and theoretical issues raised in this special issue of Culture, Medicine, and Psychiatry provide a unique opportunity to re-open forgotten topics and interconnect different disciplinary vocabularies (history, psychiatry, epidemiology, ethnography), as well as to debate the politics of diagnosis, hegemonic and counter-hegemonic knowledge, bureaucratic violence, and what "mental health" is becoming. The guest editors' decision to take the sphere of global mental health as their starting point and then to confront the field's

Roberto Beneduce

roberto.beneduce@unito.it

1 Department of Cultures, Politics, and Society, University of Turin, Lungo Dora Siena 100, Turin 10153, Italy 
presuppositions and assertions with thick ethnographies (including Brazil, Ghana, India, Senegal, Zimbabwe, and Palestine) is particularly striking. Why is global mental health so pivotal yet so contested? What explains the strong ethical and political importance of improving people's mental health yet our questionable ability to do so? In this commentary, I will raise questions with which I have been engaging in a sort of epistemological duel for some time now. More particularly, I would like to explore the issue of global mental health (GMH) against the background of other healing techniques and knowledge, and to consider the production of suffering and mental disease.

Investigating the genealogy, rhetoric, and vocabulary of global mental health, as Anne Lovell, Ursula Read and Claudia Lang do in the introduction to this issue, as well as Dominique Béhague in her article, helps shape psychiatric disorder, whatever it is, as an "interdisciplinary" phenomenon, in Roland Barthes's sense of "creating a new object, which belongs to no one" (1972:72). Dörte Bemme's paper on "Theory of Change," for its part, confirms that only a flexible and pragmatic approach can serve such different theoretical and social contexts and constantly changing issues. Other writers, too, have pointed to this: patients' needs for care, the transformation of family structure, moral dimensions of disease and treatment, cultural differences and the reciprocal contagion of healing strategies, rising inequities in Western societies, volatile dimensions of citizenship, the value of human life and so on (Butler and Judith 2009; Del Vecchio Good and Good 2003; Fassin 2018; Nguyen and Peschard 2003; Romero and Margolis 2005).

All of the articles in this issue make explicit that, as with ethnography (Clifford 1986:7) the truths of psychiatry-any psychiatry - are but "partial truths." The history of madness has familiarized us with this horizon of inescapable indeterminacy. Nicolas Henckes' analysis of schizophrenia (this issue) brilliantly explores a particular aspect of this indeterminacy; namely, how clinical epistemology, "infrastructural" dimensions of diagnosis, epidemiological surveys in different societies, and global mental health overlap in the building of a (temporarily) hegemonic diagnostic category. This is an important point if one wants to unveil the deep and often messy links between expressions of suffering, social anxieties, international cooperation programs, and, above all, the ceaseless metamorphosis of private/public frontiers. Social scientists have a specific responsibility to look for and see these hidden connections (I deliberately refer to connections, and not causal or deterministic relations). ${ }^{1}$ Let me evoke some of them.

\footnotetext{
1 See, for instance, Santner's superb analysis on the relationship between Schereber's paranoia and the building of the German Nazi nation-state (1996). Other symptoms, such as "silence of the catatonic", can be the expression of social contradictions and institutional violence: "If the group is going to structure itself in terms of a rejection of the spoken word, what response is there apart from silence?" (Guattari 1984:14). On this, see also Basaglia (1987).
} 


\section{Hidden Contradictions}

The decade of the nineties was a turning point in the globalization of healthcare strategies. Several important epidemiological studies on the so-called "global burden of disease" and research on inequity in access to care were conducted during that period, mostly with funding from the World Bank and other international agencies involved in promoting different actions to support public institutions in low-income countries. Today, the GBD, QALYs, DALYs, YLDs, and GMH are widely used acronyms that mark the success of a globalized (or, if we follow Summerfield [2012], a "Western") lexicon of mental health issues that mixes pragmatic, cognitivist, and community-based approaches to psychiatry. But scholars cannot ignore that at the same time, during these very years, another international project, the structural adjustment programs (SAP) launched in the Eighties by the International Monetary Fund (IMF) and the World Bank, was producing long-term effects. It remains astounding that, within these institutions, policies concerned with health and unequal access to treatment could exist in parallel with programs that imposed on poor countries the devaluation of currency, reductions in government expenditure for basic services, increases in the prices of services, and privatization of essential services, including health. "Neoliberalism" and "international debt" became the haunting leitmotifs of a new, economic, colonialism, with a tragic resonance in the lives of many. Within a few years, the countries directly affected by Structural Adjustment experienced widespread collapses in levels of wellbeing and employment, the worsening of child and maternal health, and a corollary increase in social uncertainty, disease, and violence (Abouharb and Cingranelli 2006; Forster et al. 2019; Lugalla 1995; Pfeiffer and Chapman 2010; Sadasivam 1997; Thomson, Kentikelenis and Stubbs 2017). Some years later, one could speculate whether the experts of the structural adjustment programs were the same men and women involved in predicting the "global burden of depression."

I present these thoughts somewhat sardonically because critiques of global mental health find their legitimacy within these broader neo-colonial economic contradictions that have generated suffering and social uncertainty, while simultaneously promoting health programs and better access to care. Hanna Kienzler's considerations of "practice-based evidence" (this issue) only aggravate this rancor when she quotes statements made by WHO and other scholars about the "unparalleled opportunities" offered by war, conflict and disaster, to improve, reorganize and reform mental health programs. These statements express what I call "humanitarian realism," or the practical stance of experts, NGOs, and political leaders that allows them to accept these costs and transform tragedy, death, and loss into policy opportunities. Yet this stance hardly expresses the points of view of people who have experienced mass rape, other large-scale violence, poverty, hunger, and the destruction of their social fabric. Furthermore, the ambit of international agencies is very far-removed from the concerns of those who work daily on the long-term psychological effects of mass atrocities, collective trauma and dispossession. The gap between the perspective of international agencies and the historical consciousness of the "wretched" (Fanon 2004) is shockingly massive. 
We might ask ourselves, again sardonically, whether the programs of these international agencies are merely a new version of Kipling's "white man's burden". The emerging question here concerns the kinds of health and care the World Bank actually envisions.

\section{Hidden Unknowns}

Henckes's article also shows how schizophrenia constitutes a true "global" mental health issue. Many actions made this globalization possible, among them the trivialization of other idioms of suffering, healing knowledge, and languages. Emil Kraepelin's so-called "transcultural" psychiatric conclusions about Dementia Praecox, following his short period of study in Java in 1904, epitomize this very well. He held that the auditory hallucinations of Balinese patients were less common and less elaborate in content than those of European patients because their language was simpler and poorer than European languages. Since Kraepelin's research, scholars and practitioners have shown many times over how non-European cultures were trivialized in some cases, mummified and criminalized in others (Fanon 2004), or simply pathologized (Vaughan 1991). Antonio Gramsci (1891-1937) reminds us that élites always think of the subaltern in terms of the pathological or barbarian, not so very differently from what happened in colonies or happens today in Brazil for sexual behavior of marginalized youth (see Béhague, this issue). The history of psychiatry, including colonial ethnopsychiatry, provides many examples of this view (Gibson and Beneduce 2017).

But another issue arises in the background of these theories: the inability to see other connections. Suzanne Taïeb's work exemplifies this (Taïeb 1939). In her medical thesis supervised by the French colonial psychiatrist Antoine Porot at the Blida asylum (Algeria), this brilliant young psychiatrist qualified the content of the delusions and hallucinations of the Algerian women she encountered as "implausible details". But the content of their delusions consisted of feeling persecuted or haunted by French men and soldiers, or influenced by "external actions". The French psychiatrists, as well as Taïeb, did consider these to be signs of schizophrenia and the indigenous idea of being influenced by invisible forces to be just as symptoms, yet they ignored the political nature of the fears and suspicions of these women. This raises intriguing questions for research on the political significance of symptoms such as the feeling of "being acted upon" (Beneduce 2018; de Martino 2015), e.g. by analyzing the synecdochic value of persecutory ideas, and on the "palimpsest nature" of psychiatric disorders among migrants (Beneduce 2016). ${ }^{2}$

A second consideration concerns the expression "better access to care," often translated in GMH practice as "access to psychotropic drugs." The syllogism an investigator in a London research program offered Bemme ("in order to reduce

\footnotetext{
2 This perspective can be applied to other issues, such as "racial melancholy" (Cheng 1997; Butler 2003; Eng and Kazanjian 2003). As the authors suggest, even if melancholia and depression are not the same thing, the possibility of recognizing a political value to melancholia and the impossibility to forgetting, constitutes a crucial issue. On political meaning of symptoms, see Skultans (1997).
} 
mental health problems in people that have depression and alcohol disorder, you need to deliver care. In order to deliver care, you need care to be available. In order for care to be available you need to make drugs available") would seem to confirm this otherwise contested equation. In fact, psychiatrists continue to administer psychotropic drugs without always knowing their effects or the mechanism behind many of them; in short, despite the uncertainty surrounding them. And Henckes's study confirms the uncertainty around the classification of mental disorders suggested by the fluidity of diagnostic categories and recent success of the "dimensionality" notion. An example is the joint prescription of Olanzapine (an atypical anti-psychotic drug) and Citalopram (a Selective Serotonin Reuptake Inhibitor, or SSRI), which increases the effect of the latter on depression, although pharmaceutical information simply states that the mechanisms of this interaction "are not fully understood." Furthermore, Citalopram is increasingly prescribed "off-label" for disorders such as diabetic neuropathy, premenstrual dysphoria, and dysmorphophobia, among others (Fairman and Curtiss 2010; Vijay, Becker, and Ross 2018). Instead of recognizing that little is understood about mind processes and mental disorders (Summerfield 2012), many health workers and professionals treat patients' problems much like sorcerer's apprentices. "Side effects" thus becomes a euphemism for hiding the serious consequences of many treatments, often denounced by psychiatric survivors and patients' rights movements, as Lovell, Read, and Lang recall in their introduction.

\section{Hidden Violence}

Just as fundamental as infrastructures is the "regime of representations" (Rojas 2002) by which diagnostic labels are legitimized and the complicit silence of practitioners and others about the limits and contradictions of diagnosis and treatment. From the first edition of the DSM (1952) through to the latest (2013), the number of psychiatric diagnostic categories has continually expanded, from 106 to 374 (Cohen 2016:2). This begs the question of how (or if) so many new psychiatric disorders have actually been discovered in recent decades. Can practitioners differentiate between disorders better than before? Put differently, is diagnostic inflation based on new knowledge or is it the expression of the endless struggle among representations and theories, between hegemonies and counter-hegemonies, as the recent fall of DSM and rise of the National Institute of Mental Health's Research Domain Criteria (RDoC) suggest? (Clark et al. 2017; Hacking 1995, 2006; Rose 2018). Michel de Certeau's reflection is particularly illuminating here for understanding historically the social anxiety governing the succession and proliferation of diagnostic labels for what remains difficult to domesticate:

History would be this progressive initiation into the structures of the asylum, each social discourse in turn effacing the symptoms of what has engendered it. Culture would intercede by displacing the representations: (for example, we no longer believe in the devil [...]). But, while effacing an imaginary (that has become archaic because of these very displacements), culture only believes in 
working to "take care of," or to suppress, what in reality it takes pride in camouflaging in another way, and better. From this perspective, successive "therapies" would be spread over history as means of "healing" - of taking care of or of progressing - that would always function as means of concealment (298-99).

Hence, the need for a "history of hesitations", as Clifford suggests for anthropology (2008), rather than simply the history of conquests and successes in psychiatric knowledge.

If the asylum, and later, the training of health workers in standardized diagnostic instruments and classification systems were essential tools for globalizing schizophrenia, other diagnostic categories, particularly depression and PTSD, reveal different infrastructures and regimes of representation. Although a thorough exploration is beyond the scope of this commentary, a few observations can be made. In the case of depression, the hegemonic representation of "good" mood and the proliferation of anti-depressants made possible its globalization (Bullard 2002). The PTSD infrastructure, on the contrary, involves generalization of a diagnosis whereby categories of trauma and traumatic memory are unquestioned concepts for labeling a multiplicity of heterogeneous, incomparable situations, experiences, and disorders. An imaginary architecture connects highly disparate events and experiences, unified under a debatable theory of "traumatic memory." The more numerous the "experts on trauma", the more the empire of trauma grows (Fassin and Rechtman 2007), as PTSD cases are increasingly diagnosed everywhere. PTSD is thus far the most impressive example of a globalized diagnosis.

My experience in the West Bank city of Ramallah, from 2004 to 2006, was in this sense instructive. A social worker at the Treatment and Rehabilitation Center for Victims of Torture (TRC), where I was teaching courses on political violence, memory, and therapy, implored me to help her learn about EMDR (Eyes Movement Desensitization and Reprocessing). ${ }^{3}$ I was deeply surprised. How can such a therapy work, I asked myself, in a context of unending humiliation, violence, and daily traumatic experience? Is EMDR able to cure traumatic history and the traumatic ongoing present of Palestinian people? Or does it simply veil the violence of history? How helpless did the social worker actually feel and how much had her historical consciousness been colonized by a hegemonic trauma discourse that assumed EMDR could work in Palestine? What kind of (professional) subjectivities built through humanitarian discourse had produced this? (Fassin 2008). Kienzler might agree with my view that to speak of PTSD in Palestine, with its ongoing trauma of over 70 years' duration, is to run the risk of replacing tragedy with farce. And to speak of a Palestinian "Ministry of Health" in the absence of a state, sovereignty, and free mobility, risks masking the atrocious necro-politics that oppresses the civilian population (Mbembe 2013). Just as Fanon refused to work in a context of "systematized dehumanization" and "permanent assault on the most commonplace values" (Fanon 1967:54), GMH, too, should consider the contradictions surrounding PTSD instead of simply adopting and deploying scales to measure

\footnotetext{
${ }^{3}$ On the definition and (presumed) efficacy of EMDR, see the work by the Francine Shapiro (1948-2019), the psychologist who invented this technique (Shapiro 1989).
} 
trauma, depression or suffering produced by a political oppression that is obvious to everyone concerned.

\section{Hidden Politics}

The case Claudia Lang discusses with regard to Kerala, India (this issue) provides other perspectives that suggest interconnections between morality, government intervention and GMH. It offers the possibility of rethinking what medicalization is and can do. With regard to the last point, medicalization can prove useful if conceived as an opportunity for people to meet health workers, dialogue with them about their lives and their loneliness, and, of course, receive appropriate medical treatment. In this sense, medicalization and psychologization might act as a strategy of recognition, thereby helping people to experience other "subject positions" (Oliver 2003), as in the case of the young Brazilian women Béhague studied. But if medicalization translates the project of reducing suffering and its treatment down to only one perspective (that of psychiatry or of GMH), if psychologization and medicalization operate according to a class code, as Béhague recalls (this issue), ${ }^{4}$ then it becomes difficult to attribute to it the power "to provide an idiom to critique a family's moral economy." This simply amounts to substituting one moral economy for another. And the case of Umma, described by Lang, epitomizes this. The beginning of Umma's loneliness and the absence of care, once provided by her sons, belong to a precise era. Yet oddly enough, the health worker omits this from discussion or perhaps has simply forgotten that period of time: "Although they [the sons] had returned [from abroad] from time to time in order to marry, father children and see their mother, a court case related to their political activity in a communist organization in Kerala, prevented them from returning." I see this time as the breaking point, the origin of a crisis in family ties and of the "lack of care". This perfectly exemplifies how political repression can generate interpersonal conflicts, abandonment, and suffering. It is not strange that Sanjeev, the "representative of the state" Lang met, does not work with this issue. Simply put, he cannot. What is more interesting is that the administration of drugs and the emphasis on a psychiatric condition (Umma's depression) and, above all, the making of negative moral comments about family inadequacy, hide the other (political) issue. Psychiatric diagnosis often does this; it names a disorder and at the same time hides another issue, difficult or impossible to evoke.

\footnotetext{
4 “As anthropologist Fernando Duarte has cogently argued, Brazil's long-standing two-tiered systempsychoanalysis for the rich and hospitalization for the poor-has perpetuated a late 19th and early 20th century medical episteme that continues to juxtapose upper class 'intellectualism' with the 'retrograde' psyche of the underclass" (Béhague, this issue).
} 


\section{Hidden Ontologies}

On the basis of what I call a hesitant and critical ethnopsychiatry, I will add some concluding remarks on "traditional medicine," GMH and ethnopsychiatry, starting with the issues Anne Lovell and Papa Mamadou Diagne (in Senegal) and Ursula Read (in Ghana) convincingly and lucidly analyze in their papers. Their research evinces in particular the complex relationship between mental health workers and patients, on one hand; and between what we usually define as healers and traditional medicine and patients, on the other. The association between health and "culture" remains ambivalent and its definition at times anodyne. The 2014 Lancet document on "Culture and health", for instance, while providing a strong, critical perspective on cultural difference, illness and psychiatric diagnosis (2014:1614), nevertheless recommends the following definition of culture: "The shared, overt and covert understandings that constitute conventions and practices, and the ideas, symbols, and concrete artifacts that sustain conventions and practices, and make them meaningful." It endorses statements such as: "cultural practices (e.g. states of possession) can provide acceptable cultural mediums for expressing anxiety, loss, and helplessness." These definitions miss what culture always is: a field of struggle among competing hegemonic and counter-hegemonic symbols, vocabularies, practices, and definitions; a political battle between minority groups and a dominant élite, or between individuals and their own culture, to claim the right to difference (not to mention of Roy Wagner, Philippe Descola, and Eduardo Viveiros de Castro' definitions). And it forgets another issue, too: the relationship between nation state formation, ethno-cultural difference and race-making (Marx 1998; Segato 2007, 2014, 2015).

States of possession are much more than "cultural mediums for expression of anxiety, loss, and helplessness." They display another body, another relationship with the world, another phenomenology of experience, and what is more, another therapeutic technique. Some months ago, I witnessed an ndoep ceremony in M'Bour (Senegal). ${ }^{5}$ Long negotiations around the religious (i.e. Muslim) legitimacy of the ceremony; dramatic manifestations of suffering in some participants (some experienced dramatic crisis for many hours); the intense participation of a crowd (about two hundred people) over 4 days; animal sacrifices (three cows, seven goats, and a multitude of chickens), and finally, the recovery of an ordinary condition for the people in need of treatment. What was this multifaceted healing theater displaying? It is not possible to provide a detailed analysis here, but Lovell and Diagne's ethnography offers thick suggestions about this field, inviting the readers to interrogate the "sheep-obsession" of some patients and carers, the intensive use of references to the animal world and perspective, to sacrifice and metamorphosis, or to concepts of animal-becoming, reminding us of the key role of specific ontologies of the body and experience in ritual healing processes.

The Fann/Dakar School—today barely a memory, an impossible heritage (Kilroy-Malrac 2019), as nothing of that experience still lives; or a haunting revenant (Kilroy-Malrac 2014) — began at the end of the fifties with research on

\footnotetext{
5 See Lovell and Diagne, this issue.
} 
these types of rituals. Henri Collomb and his Fann School colleagues soon discovered the impossibility of translating and explaining them in solely medicopsychological terms. An African psychiatrist, Thomas Adeoye Lambo (1965:1390), calmly but firmly declared that Western psychiatry reveals its "moral arrogance" when it thinks of applying its categories and its ideas everywhere. Has GMH included such caution in its agenda? Moreover, starting with Lambo's observations, it is important today to interrogate what the "return of cultures" might even suggest in fields such as migration, asylum politics or refugee studies (Beneduce 2018), what "traditional medicine" expressed in the colonial past (Feierman 1985, 1995) and, above all, what the tenacious presence of other repertoires of myths says about the "foreclosed" history of modern nation states (Platt 2002; Segato 1998).

\section{Hidden Histories}

Both Lovell and Diagne, and Read, raise another fundamental issue: the complex transformation of healing knowledge, the violence of its practices, and above all the difficult relationship between health professionals on one side, and healers on the other. Three short considerations are due. First, traditional medicine as a "system" doesn't exist (Last 1981). And if it is urgent to deconstruct the term "traditional medicine" for epistemological reasons, the case Read considers rightly reveals another issue. "The Prophet," his gestures, and his rhetoric originate from Pentecostalist symbols and texts, and have little to do with a presumed African medical tradition of plants, divination, symbols and ritual healing. At the most, they combine these various hetero-logical profiles in a singular and unpredictable way. The Africanist anthropologist and priest, Eric De Rosny (1981), saw re-configuration as the main trait of traditional medicine. "Traditional" healing techniques and new religious imaginaries are among the most significant traces of the globalizing project realized by the missionary venture and evangelization (and colonization). ${ }^{6}$ So when social workers and mental health professionals encounter faith, or traditional healers like "the Prophet," they see themselves reflected in a sort of temporal, deforming, mirror, in which the entire history of evangelization and colonization is imbricated into what is by now termed "traditional medicine." Is this historical conundrum and is this kind of historical consciousness discussed when health workers are invited to "collaborate" with faith and traditional healers?

\footnotetext{
${ }^{6}$ Let me quote a significant passage from Quijano: "In the beginning, colonialism was a product of a systematic repression, not only of the specific beliefs, ideas, images, symbols or knowledge that were not useful to global colonial domination, while at the same time the colonizers were expropriating from the colonized their knowledge, especially in mining, agriculture, engineering, as well as their products and work. The repression fell, above all, over the modes of knowing, of producing knowledge, of producing perspectives, images and systems of images, symbols, modes of signification, over the resources, patterns, and instruments of formalized and objectivized expression, intellectual or visual. It was followed by the imposition of the use of the rulers' own patterns of expression, and of their beliefs and images with reference to the supernatural. These beliefs and images served not only to impede the cultural production of the dominated, but also as a very efficient means of social and cultural control, when the immediate repression ceased to be constant and systematic" (2007:169).
} 
Second, traditional healers, in order to survive in the modern postcolonial state, had to accept the inexorable bureaucratization of their knowledge; what is euphemistically called "professionalization" (Beneduce 2013; Dozon 1987; Fassin 1988). There is a long-standing ambivalence toward traditional medicine. Humiliated, criminalized and trivialized, even by socialist African governments (in Mozambique and the People's Republic of Congo) who have qualified it as "obscurantism," it has more recently been rediscovered, valued, and promoted, only to be, in this "recognition," relegated to a marginalized area of state discourse. At the same time, people stubbornly continue to use its remedies and ceremonies, even when more expensive, while questioning at the same time its ability to answer to all their needs, anxieties, and discontents. Have we a satisfying answer as to why? ${ }^{7}$

Third, many human rights discourses emphasize the risk "traditional" treatment poses for the lives of patients, a risk denounced in many countries, from Morocco to Ghana, Gabon to Uganda. This potential arena for developing from the ground up presents an important, and ultimately symmetrical and reciprocal opportunity for collaboration between minority groups and human rights organizations both in Western and non-Western countries, which denounces the violence of both psychiatry (lobotomy, ECT, restraints, unnecessary use of drugs, involuntary hospitalization) and some kinds of ritual therapies (imposed fasting, restraint, violent treatment), and working on this dark side of "healing." Is this comparative issue on the GMH agenda?

In conclusion, criticism of GMH stems from the fact that many interventions recently implemented by international agencies continue to adopt standardized scales and Western models of mental health while remaining silent about other urgent issues: organized state violence in modern democracies (torture, the tragedy of "administrative" detention, and so on), humanitarian hypocrisy, and rising discrimination against migrants along nation-state borders (US, Europe). In other words, it is imperative to promote new critical articulations between (politically based) cultural psychiatry or ethnopsychiatry and international collaborative research, by including on the GMH agenda the issue of the devastating impact that technologies of anti-citizenship (Inda 2006) have on people and their mental health; as does the tragedy of racism, in all its expressions, from "racial prescription" of drugs (Inda 2014) to the vertigo of racial violence in US and Europe up through what I call the "crypto-racism" of health and other institutions. I fully agree with Cheng that multiculturalism is just a "utopian no-place where the pathologies of race and gender miraculously heal themselves. The very idea of the melting pot serves to celebrate assimilation while continually remarking difference" (1997:51-52). Her suggestion could be applied to many programs concerning mental health in multicultural societies. It is impossible, in other words, to separate the political, the cultural, and the psychological. If disconnection has been "a large, psychological, political and socioeconomic problem for Blacks in the twenty-first century" (Ogunyemy 2002:663), it is just as much of a common, widespread

\footnotetext{
7 The patients' voices, memories and gestures in Ce qu'il reste de la folie, the magnificent film by Joris Lachaise on madness and healing in Thiaroye Psychiatric Hospital (Senegal) are a vivid and unique testimony to this issue.
} 
problem for minorities and the oppressed. Is this "disconnection" the disease to be taken into consideration and treated?

\section{Compliance with Ethical Standards}

Conflict of interest Roberto Beneduce declares that he/she has no conflict of interest, and that didn't receive any grant or honorarium for this research and this article.

Ethical Approval This article does not contain any studies with human participants performed by any of the authors.

\section{References}

Abouharb, M. Roswan, and David L. Cingranelli

2006 The Human Rights Effects of World Bank Structural Adjustment, 1981-2000. International Studies Quarterly 50:233-262.

Achille, Mbembe

2013 Necropolitics. Public Culture 15(1):11-40.

Anthony, Marx J.

1998 Making Race and Nation. Cambridge: Cambridge University Press.

Barthes, Roland

1972 The Rustle of Language. Berkeley, CA: University of California Press.

Basaglia, Franco

1987 Psychiatry Inside Out: Selected Writings. In N. Scheper-Hughes and A. M. Lovell, eds. New York: Columbia University Press.

Beneduce, Roberto

2013 Fantasmagories de la Cure. Routinisation de la vision et 'textes cachés' dans les thérapies rituelles (Cameroun). Cahiers d'études africaines, LIII 212:895-933.

2016 Traumatic Pasts and the Historical Imagination. Symptoms of Loss, Postcolonial Suffering, and Counter-Memories. Transcultural Psychiatry 53(3):261-285.

2018 Une nouvelle bataille de vérité. Discours sorcellaires, cicatrices corporelles et régimes de crédibilité dans le droit d'asile. Cahiers d'études africaines 231(232):763-792.

Briggs, Charles, and Mantini-Briggs Clara

2000 Bad Mothers and the Threat to Civil Society: Race, Cultural Reasoning, and the Institutionalization of Social Inequality in a Venezuelan Infanticide Trial. Law and Social Inquiry 25(2):299-354.

Bullard, Alice

2002 From Vastation to Prozac Nation. Transcultural Psychiatry 39(2):267-294.

Butler, Judith

2003 Afterword: After Loss, What Then? In Loss: The Politics of Mourning. D.L. Eng and D. Kazanjian, eds., pp. 467-474. Berkeley, CA: The University of California Press.

2009 Frames of War. When is a Life Grievable? New York: Verso.

Cheng, Anne Alin

1997 The Melancholy of Race. The Kenyon Review 19(1):49-61.

Clark, Lee Anna, Bruce Cuthbert, Roberto Lewis-Fernández, William E. Narrow, and Geoffrey M. Reed

2017 Three Approaches to Understanding and Classifying Mental Disorder: ICD-11, DSM-5, and the National Institute of Mental Health's Research Domain Criteria (RDoC). Psychological Science in the Public Interest 18(2):72-145.

Clifford, James

1986 Partial Truths. In Writing Culture. The Poetics and Politics of Ethnography. J Clifford and GE Marcus, eds., pp. 1-26. Berkeley: University of California Press.

Cohen, Bruce M. Z.

2016 Psychiatric Hegemony. A Marxist Theory of Mental Illness Auckland: Palgrave Macmillan. de Certeau, Michel

1988 The Writing of History. New York: Columbia University Press. 
de Martino, Ernesto

2015 Magic: A Theory from the South. Chicago: HAU Books.

De Rosny, Eric

1981 Les Yeux de Ma Chèvre. Paris: Plon.

1996 La Nuit, les Yeux Ouverts. Paris: Éditions du Seuil.

Del Vecchio Good, Mary-Jo, and Byron J. Good

2003 Introduction: Culture in the Politics of Mental Health Research. Culture, Medicne and Psychiatry 27(4):369-371.

Didier, Fassin

2008 The Humanitarian Politics of Testimony: Subjectification Through Trauma in the IsraeliPalestinian Conflict. American Anthropologist 23(3):531-558.

2018 Life. A Critical User's Manual Cambridge: The Polity Press.

Dozon, Jean-Pierre

1987 Ce que valoriser la médecine traditionnelle veut dire. Politique Africaine 28:9-20.

Eng, David L., and David Kazanjian, eds.

2003 Loss: The Politics of Mourning. Berkeley, CA: The University of California Press.

Fairman, Kathleen A., and Frederic R. Curtiss

2010 Regulatory Actions on the Off-Label Use of Prescription Drugs: Ongoing Controversy and Contradiction in 2009 and 2010. JMCP Journal of Managed Care Pharmacy 16(8):629-639.

Fanon, Frantz

1959 Toward the African Revolution. New York: Grove Press.

2004 The Wretched of the Earth. New York: Grove Press.

Fassin, Didier

1988 Traditional Medicine and the Stakes of Legitimation in Senegal. Social Science and Medicine 27(4):353-357.

Fassin, Didier, and Richard Rechtman

2009 The Empire of Trauma: An Inquiry into the Condition of Victimhood. Princeton: Princeton University Press.

Feierman, Steven

1985 Struggles for Control: The Social Roots of Health and Healing in Modern Africa. African Studies Review 28(2/3):73-147.

1995 Healing as Social Criticism in the Time of Colonial Conquest. African Studies 54(1):73-88.

Forster, Timon, Alexander Kentikelenis, Bernhard Reinsberg, Thomas Stubbs, and Lawrence P King

2019 How Structural Adjustment Programs Affect Inequality: A Disaggregated Analysis of IMF Conditionality, 1980-2014. Social Science Research 80:83-113.

Gibson, Nigel, and Roberto Beneduce

2017 Frantz Fanon, Psychiatry and Politics. London: Rowman and Littlefield.

Guattari, Felix

1984 Molecular Revolution. Psychiatry and Politics New York: Penguin Books.

Hacking, Ian

1995 Reinventing the Soul: Multiple Personality and the Sciences of Memory. Princeton, NJ: Princeton University Press.

2006 Making Up People. London Review of Books 28(16):23-26.

Inda, Jonathan-Xavier

2006 Targeting Immigrants. Government, Technology, and Ethics Malden: Blackwell.

2014 Racial Prescriptions: Pharmaceuticals, Difference, and the Politics of Life. Farnham: Ashgate.

James, Clifford

2013 Returns. Becoming Indigenous in the Twenty-First Century Cambridge, MA: Harvard University Press.

Kentikelenis, Alexander E., Thomas H. Stubbs, Stuckler David, McKee Martin, and Lawrence P. King

2017 The Impact of IMF Conditionality on Government Health Expenditure: A Cross-National Analysis of 16 West African Nations. Social Science and Medicine 174:220-227.

Kilroy-Malrac, Katie

2014 Speaking with Revenants: Haunting and the Ethnographic Enterprise. Ethnography 15(2):255276.

2019 An Impossible Inheritance. Postcolonial Psychiatry and the Work of Memory in a West African Clinic Oakland: University of California Press. 
Lambo, A. Thomas

1965 Neuropsychiatric Observations in the Western Region of Nigeria. British Medical Journal $15: 1388-1394$

Last, Murray

1981 The Importance of Knowing About Not Knowing. Social Science and Medicine 15B:387-392.

Lugalla, Joe H.P.

1995 The Impact of Structural Adjustment Policies on Women's and Children's Health in Tanzania. Review of African Political Economy 22(63):43-53.

Nguyen, Vinh-Kim, and Karine Peschard

2003 Anthropology, Inequality, and Disease: A Review. Annual Review of Anthropology 32:447-474.

Peabody, John H.

1996 Economic Reform and Health Sector Policy: Lessons from Structural Adjustment Programs. Social Science and Medicine 43(5):823-835.

Pfeiffer, James, and Rachel Chapman

2010 Anthropological Perspectives on Structural Adjustment and Public Health. Annual Review of Anthropology 39:149-165.

Platt, Tristan

2002 El feto agresivo: parto, formación de la persona y mito-historia en los Andes. Estudios Atacameños 22:127-155.

Quijano, Aníbal

2005 A colonialidade do saber: Eurocentrismo e ciências sociais. Perspectivas latino-americanas Buenos Aires: CLACSO.

2007 Coloniality and Modernity/Rationality. Cultural Studies 21(2-3):168-178.

Rojas, Cristina

2002 Civilization and Violence. Regimes of Representation in Nineteenth-Century Colombia Minneapolis: MN, Minnesota University Press.

Romero, Mary, and Eric Margolis, eds.

2005 The Blackwell Companion to Social Inequalities. New York: Wiley Blackwell.

Rose, Nicholas

2018 Our Psychiatric Future. London: Polity Press.

Sadasivam, Bharati

1997 The Impact of Structural Adjustment on Women: A Governance and Human Rights Agenda. Human Rights Quarterly 19(3):630-665.

Santner, L. Eric

1996 My Own Private Germany Daniel Paul Schreber's Secret History of Modernity. Princeton (NJ): Princeton University Press.

Segato, Rita Laura

1998 The Color-Blind Subject of Myth; or Where to Find Africa in the Nation. Annual Review of Anthropology 27:129-151.

2007 La nación y sus otros. Buenos Aires: Prometeo.

2014 L'Edipe noir. Paris: Payot.

2015 La crítica de la colonialidad en ocho ensayos. Y una antropología por demanda. Buenos Aires: Prometeo.

Shapiro, Francine

1989 Efficacy of the Eye Movement Desensitization Procedure in the Treatment of Traumatic Memories. Journal of Traumatic Stress 2:199-223.

Skultans, Vieda

1997 A Historical Disorder: Neurasthenia and the Testimony of Lives in Latvia. Anthropology \& Medicine 4(1):7-24.

Summerfield, Derek

2012 Afterword. Against 'Global Mental Health’. Transcultural Psychiatry 49(3-4):519-530.

The Lancet Commission

2014 Culture and Health. Lancet 384(1):1607-1639.

Thomson, Michael, Alexander Kentikelenis, and Thomas H. Stubbs

2017 Structural Adjustment Programmes Adversely Affect Vulnerable Populations: A SystematicNarrative Review of Their Effect on Child and Maternal Health. Public Health Review 38(13):2-18. 
Vaughan, Megan

1991 Curing their Ills. Colonial Power and African Illness Stanford: Stanford University Press. Vija, Aishwarya, Jessica E. Becker, and Joseph S Ross

2018 Patterns and Predictors of Off-Label Prescription of Psychiatric Drugs. PLoS ONE 13(7):1-14.

Publisher's Note Springer Nature remains neutral with regard to jurisdictional claims in published maps and institutional affiliations. 